\title{
Managing Admission in Saudi Universities: A System Approach
}

\author{
A. Alotaibi, A. Ayesh, and R. Hall
}

\begin{abstract}
This research aims at the development of a framework for designing a proposed admission system in the Saudi universities.

This study is based on results of another paper that revealed that the current admission system in the Saudi universities needs to develop. This due to the current system for admission in Saudi universities is not comprehensive, and not relevant.

The study recommends applying modern approaches related to DSS (such as; the proposed system) in order to improve the efficiency of the admission system in the Saudi universities.
\end{abstract}

Index Terms-Decision support systems (DSS), the efficiency, admission system, Saudi universities.

\section{INTRODUCTION}

Saudi universities need a smart decision support system (DSS) that can be applied on the national level for all Saudi universities including the private universities that will remove challenges and problems. The proposed system will consider many factors and assign a new grade and major to each student, either Saudi or non-Saudi, who applies for admission in Saudi universities. This system will improve the quality of the admission system in the Saudi universities. Also, it will lead to optimum use of available resources and achievement of targets in the field of education in KSA.

Due to the Education system in the Kingdom of Saudi Arabia (KSA) facing some challenges and problems, this system needs to improve. This requires establishing a new admission system based on Decision Support System (EDSS) which is formally structured and designed to collect, maintain and supply relevant, reliable, and timely information to guide educational policy, planning, and the decision-making process.

Because the student introduces many requests to more than one university, the current admission system in Saudi universities gives him or her acceptance in more than one university. Doing so leads to wasting many chances for other students. The proposed system accepts only one request from each student in all universities. On the other hand, it helps the universities have only one place to receive the students' requisitions.

The research tries to achieve the following objective: "The development of a framework for designing a proposed admission system in the Saudi universities".

Therefore, the importance of this research lies in the

Manuscript received September 4, 2014; revised November 13, 2014.

The authors are with De Montfort University, Leicester, United Kingdom (e-mail: Rhall1@dmu.ac.uk). necessity of improving the quality of the admission system in Saudi universities under the rapid changes in information technology (including DSS) and rationalizing the decision-making process, and consequently, attaining the optimum exploitation of the available resources and achieving their targets. The importance of this research is based on the culture that it will be implemented in. It is intended to help in increasing the quality of the Saudi universities.

To achieve the research objective, a literature review was conducted in order to determine how to develop a framework for designing an admission system in the Saudi universities in order to improve its quality. And so, the researcher will develop a framework for designing an admission system in the Saudi universities.

In order to achieve the research objectives, the research is divided into introduction, previous studies, the conceptual outlines of the study, and a conclusion.

\section{BACKGROUND}

There is a huge demand by students who passed secondary school. They try to apply for universities and get admission in specific majors. For example, in 2010, more than 120,000 students joined Saudi universities [1]-[4]. That occurred because there are no fees for the undergraduate students in Saudi universities. Not only this, but also the student gets a monthly reward, which is around 200 Euro a month.

The impact of the society was a potent factor as well since the family issues are still strong and most families wish that their sons (girls) could get admission in universities in specific majors. Mostly, they wish that their sons (girls) get admission in medical majors, such as Medicine, Pharmacy, and Dentistry. If not, then Engineering, and if not then into other colleges such as Information Technology.

There are some governmental universities, such as King Saud University, which does not accept the secondary school grades for determining the major. Instead, they ask the students to spend one year in preparation and taking basic math, English language, and computer, and based on how the students do, the university determines the eligibility of the students for the major that he or she wishes. This system of evaluation creates big differences among government universities and adds extra overhead on the students shoulder by spending one extra year.

The private universities in KSA grant admissions more easily than governmental universities. These universities exist in many cities in KSA. The Ministry of Higher Education regulates them. However, there is a strong feeling that these 
universities are easier. Thus, many students who struggle in governmental universities switch to private ones. However, there is no transfer from private to governmental universities in general. This confirms that there is different scaling for measuring the qualifications of the students for specific major. In fact, private universities mostly accept students who have the financial capabilities and, at the same time, the determination to get specific majors.

Many foreigner students who do not speak Arabic, and get graduated from school adapt different educations systems such as International Education System which is only in private schools. In this system, the required courses and the scale for the grades are different from those in other places. "In KSA, private education is to be considered one of the elements supporting governmental education at all education levels. The General Department for Private Education at the Ministry of Education supervises private schools for boys and girls. Saudi Government provides private schools with free textbooks and an annual financial aid. The government also appoints and pays for a qualified director in every private school [1]. According to UNESCO, 6.4 per cent of students enrolled in general programs are in private schools and 70.3 per cent of students enrolled in technical and vocational programs are in private schools. As for secondary education, 13.4 per cent of students enrolled in general programs are in private schools and 61.6 per cent of students enrolled in technical and vocational programs are in private schools [1]. According to the World Bank, in 2004, 7.4 percent of students in tertiary education were enrolled in private schools [3].

\section{RELATED WORK}

There exist many studies on the role of decision support systems (DSS) to improve the efficiency of student admission systems. For instance, Elimam (1991) proposed a DSS for developing university student admission policies, whereby the needs of university decision makers and the DSS components can be determined. According to Elimam, the DSS comprises three modelling components: 3) an academic performance analysis model, which includes a Multi-Classification Analysis (MCA) and a cohort analysis; 2) models to estimate prospective secondary school graduates and demand for university graduates, which rely on demographic growth and regression analysis; and 3) a student allocation model, using a linear programming model for student allocation. Model(s) provide the DM with an iterative and flexible linkage approach of the DSS models. After a three-year experimental period, the DSS has come to enjoy positive reception by university decision makers [4]. This study focused on improving the efficiency of student admission systems in the European area.

On the other hand, Sanyal (1995) investigated the relationship between computerized information systems and increasing efficiency of university management [5]. The study proposes that an information system should be designed to contribute to the integration of procedures and files on the basis of one-time data entry into centralized common files set up to make information available on a university-wide basis. It should also adequately provide quantities of organized, detailed information on which the university administrator can base plans and make decisions, providing for automated data subsystems and automatic file cross referencing. Moreover, it should provide historical information to build and support models and reflect the overall trends of the university, thus supporting the traditional reporting requirements of the university [3]. Rather than proposing a DSS model, Sanyal furnishes the profession with guidelines to harmonize the relation between IT and a DSS model. This study concentrated on using IT in increasing efficiency of university management in the European area and ignored the impact of IT on universities admission systems.

Hamdan's study (2005) explores some of the shackles and accomplishments of women in the field of education in Saudi Arabia nowadays. According to this study, the historical socio-economic and political conditions of Saudi Arabia are an essential aspect of fathoming a woman's position in the Saudi society. The perseverance of women's exclusion from public life in contemporary Saudi Arabia is one of the most controversial debates not just among Muslims but also worldwide, as the Saudi society comes under more and more inspection internationally. In 1980, female graduates exceeded male ones in the humanities sector. University women could learn most of the alike subjects as their male counterparts' save those which might lead to their mingling with men [4]. This study explores challenges that faced women in education in Saudi Arabia.

A more IT-based model is that of Mansmann\& Scholl (2007), who propose that decision-making in the field of academic planning should include an extensive analysis of large volumes of data originating in several systems. Deans and department chairs should ensure that new specializations and programs are adequately determined thanks to new technological applications evolving from electrical engineering, computer engineering, and computer science. The management of the academic workload is concerned with distributing teaching resources to efficiently sustain the university's educational framework (faculties, degrees, courses, admission policies, teaching workload, etc.) [6]. Mansmann \& Scholl offered a methodology for evaluating educational capacity and planning its distribution and deployment and implementing it as a DSS allowing simulation and evaluation of various proposals and scenarios. The system integrates input data from reliable sources into an independent data warehouse. Graphical client front-end ensures adequate output presentation to the decision-makers by uncovering useful data details and dependencies [7]. The study gives evidence for the application of the system as an "on-the-fly" decision-support utility by the policy-makers, which leads to accelerating planning procedures, and deepens insight into the data and the underlying methodology, thus providing for a more effective academic management in Spain, a European country.

Gearing their research towards quality, Garcia-Cascales \& Lamata (2009) used the Spanish National Agency for Quality Assessment and Accreditation insights to evaluate both teaching and institutions through the Institutional Assessment Programme. Their study focuses on the external assessment phase for qualifications in the field of Industrial Engineering and specifically on the structures of the database for a DSS on the universities' rankings. In particular, reaching the weight 
of the criteria and definition of the linguistic labels used in the external assessment phase are emphasized [8]. This study concentrated on using DSS in managing educational capacity utilization in general.

Similar to Garcia-Cascales \& Lamata (2009) in taking advantage of quality in higher education, Bresfelean, Ghisoiu, Lacurezeanu and Sitar-Taut, (2009) argue that because of increased competition in higher education environments, universities should adopt modern Information and Communication Technologies (ICT) to achieve quality educational procedures, using more competently the collected data and developing tools to gather and direct information management in order to support managerial decision making. The collected data could be utilized to measure quality, perform analyses and diagnoses, evaluate dependency to the standards and practices of curricula and syllabi, and suggest alternatives in decision processes. Bresfelean et al. argue that data mining (DM) and DSS are well suited technologies to provide decision support in higher education environments by producing and presenting information and knowledge that would enhance the quality of educational processes and management [9]. This study, also, concentrated on using DSS in improving the educational environment in general.

Emphasising a particular measurement of quality through key performance indicators (KPI), Dahlan \& Yahaya (2010) explore the factors that form the basis of a DSS for meeting the supply and demand of an academic program, which directly caters for efficient resource management, thus contributing to a system dynamics (SD) model [10]. Dahlan \& Yahaya note that managing academic resources is a multifaceted administrative issue, arguing that the admission capacity for a degree program is determined based on the number of lecturers, total enrolled students, and facilities in the university. The formula used is the lecturer-to-student ratio. Dahlan \& Yahaya suggest that actions should be taken by universities towards harmonizing the educational capacity based on the KPIs of academic activities, which would ensure a systematic and strategic management of academic resources. This study focused on rationalising the educational capacity in universities and institutions.

Bhatti \& Adnan's (2010) study presents a challenge to the Education Management Information System (EMIS) [11], offering an EMIS, which not only aims to collect statistics from the schools by following people, models, methods, procedures, processes, rules, and regulations but also relates to the emerging computer technology to ensure that all functions work together to provide timely and dependable data to education leaders, decisions makers, planners and managers in order to efficiently perform their tasks to realize their goals. Computer technology provides technical support to the EMIS by providing the right people with the right information at the right time to make best decisions, planning, and monitoring in the best interest of the organization. This study dealt with helping decision-makers in universities in the decision making process in developing countries.

One of the most recent studies on DSS is offered by Vohra \& Dais (2011), who showed how the mechanisms of a DSS for developing student admission policies in a higher education institute or at the university help overcome the pitfalls of higher education institutions [12]. Accordingly, IT is proposed as a useful tool for achieving many goals in the field of education. However, the current study attempts to cover more than one purpose in student admission, with special application to universities in the Kingdom of Saudi Arabia. However, the current study did not provide a comprehensive approach for admission system in Saudi universities.

\section{THE CURRENT SySTEM OF UNIVERSITIES ADMISSIONIN SAUDI ARABIA (UASA)}

First of all, there is no unified secondary exam at the national level. Instead, all final grades for the secondary school are assigned by the student school locally. This creates many variations in measuring. For example, the number of teachers in KSA who teach only at the highest level is around 10,000 and this means that for the same course, there will be more than 5000 different exams. These exams make a lot of variation and in many cases, mislead the universities. In fact, it was reported in the universities that more than $5 \%$ of the students change their major after some time. Some of them have admitted that they got high grades due to some relatives or friendships or in illegal issues.

However, there is no integrated, comprehensive, and flexible admission system in Saudi universities. This situation may lead to some problems faced by students when they try to get acceptance in Saudi universities. Because the students introduce many requests to more than one university, the current admission system in Saudi universities gives them acceptance in more than one university. This wastes many chances for other students. The proposed system accepts only one request from each student in all universities. On the other hand, it helps the universities have only one place to get the students requisitions.

Therefore, the researcher will develop a smart decision support system (DSS) that can be applied on the national level for all Saudi universities including the private universities that will remove the variations and do some adjustments to the students. The proposed system will consider many factors and assign a new grade and major to each student who applies for admission. This will lead to optimum use of available resources and achieve targets in the field of education in the KSA.

\section{FRAME WORK FOR UASA}

The appropriate selection of candidates for university admission is a challenge for the administration and the subject for much debate. A fair, transparent, and effective admission system is needed for students from a growing pool of candidates.

\section{A. The Requirements of UASA}

End users (students) must register in the website in order to be able to apply for a faculty. Students, also, must submit transcripts of secondary school and must follow the application procedures specified by the ministry of higher education to which they are applying. Every student admitted as an undergraduate in any Saudi university must meet the requirements for admission that may be prescribed by the 
Ministry of Higher Education. Applicants should be advised that meeting minimum requirements will not guarantee admission at any university. Institutions may set additional requirements.

The admission employee should be able to display and search for student's requests. The administrator should has the full privileges over the website and able to make access at any time.
Universities should determine the number of students that are needed every year. This will be done according to a national policy inside the kingdom.

\section{B. Framework Design of UASA}

The framework of admission system for Saudi universities to meet the requirements and to help end users, as follows:

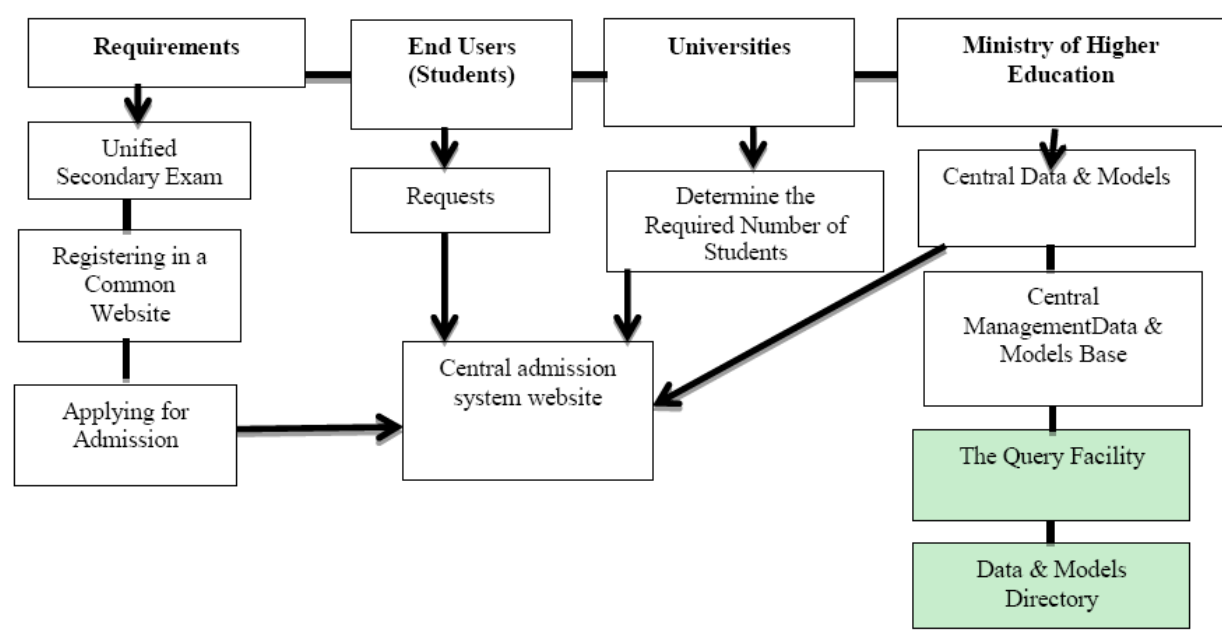

Fig. 1. Framework of UASA.

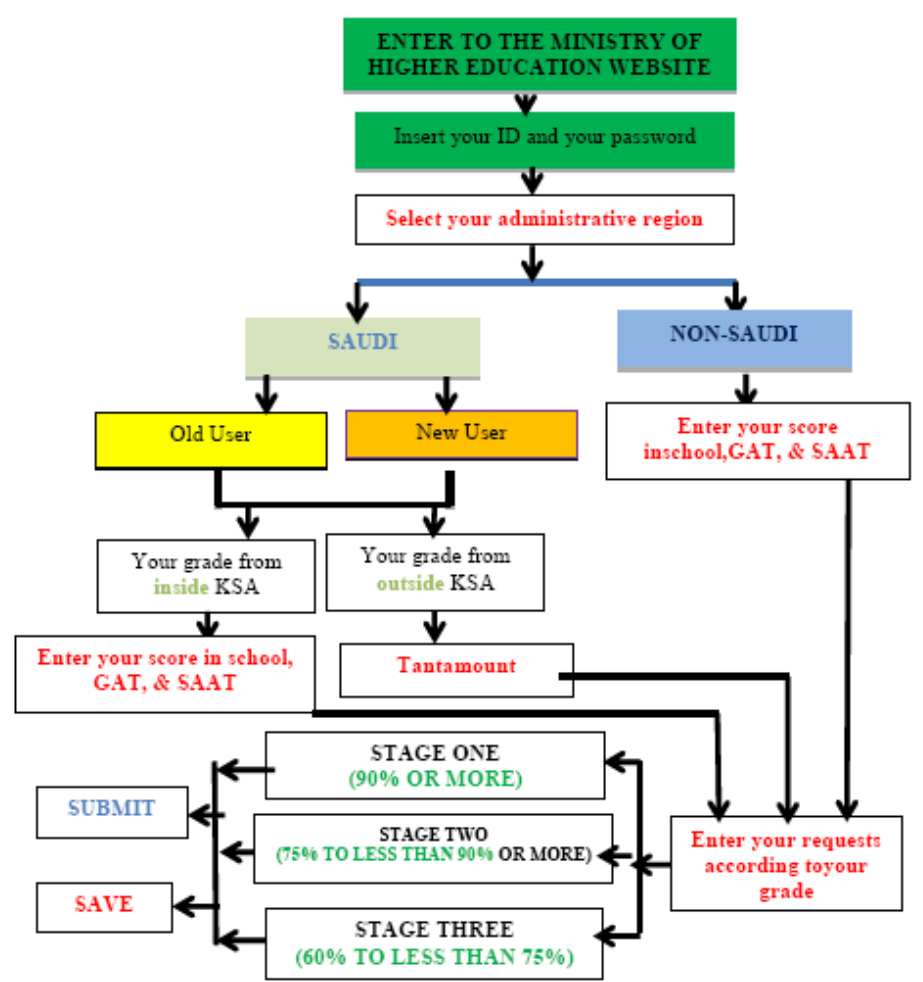

Fig. 2. Prototype of proposed framework for UASA.

\section{A PROTOTYPE FOR UASA}

A prototype is a sample, model or release of a product or system built to test a concept or process or to act as a thing to be replicated or learned from. It is a term used in a variety of contexts, including semantics, design, electronics, and software programming. A prototype is designed to test and try a new design (product or system) to enhance precision by system analysts and users. Prototyping serves to provide specifications for a real, working system rather than a theoretical one [13]. This means that the prototype is a design tool used to help create a new a system, much like a model.

There are different kinds of prototypes; some are more like rough drafts and some are more like the final version [14]. It is possible to use prototype testing to reduce the risk that a design may not perform as intended, however prototypes generally cannot eliminate all risk. There are pragmatic and practical limitations to the ability of a prototype to match the intended final performance of the product or the system and some allowances and judgments are often required before 
moving forward with a production design [15].

The prototype of this study can be explained, as follows:

To enter your requests, you should enter the central admission system within Saudi universities via inserting your ID and your password at the Ministry of Higher Education website. If the user is non-Saudi, he or she will enter his or her requests directly at stage three. Whereas, if you are Saudi, you will have two options: old user or new user. Then, if you are either an old user or a new user, you will have another two options, which are your grade from inside or outside the KSA. Then, you need to enter your requests according to your grade. There are three stages according to students' grade. Stage one for grade $90 \%$ or more (for example), Stage Two for grade $75 \%$, and more, till reaching less than $90 \%$ (for example), and Stage Three for grade $60 \%$, and more, till reaching less than $75 \%$ (for example). This can be shown in the Fig. 2:

To create an Account as a new user, you should enter the Ministry of Higher Education website and fill an application form. If you already have an account, you should update your personal data. Then, submit your form. This can be shown in the Fig. 3.

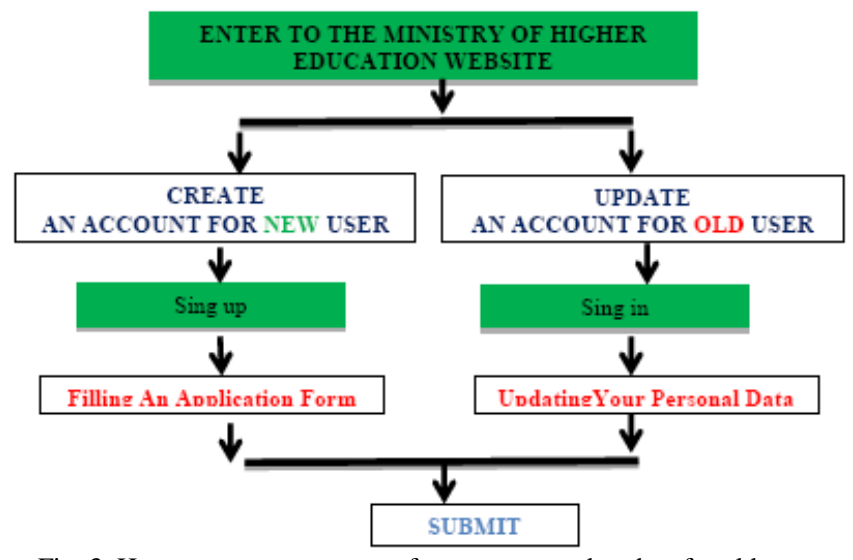

Fig. 3. How to create an account for new user and update for old user.

TABLE I: THE ADMINISTRATIVE REGIONAL DIVISIONS OF THE KINGDOM OF SAUDI ARABIA [16]

\begin{tabular}{|c|c|c|}
\hline Code Number & Region & Headquarter \\
\hline 01 & Riyadh Region & Riyadh Region \\
\hline 02 & Makkah Region & Makkah City \\
\hline 03 & Madinah Region & Madinah City \\
\hline 04 & Qasim Region & Qasim City \\
\hline 05 & Eastern Region & Eastern City \\
\hline 06 & Asir Region & Abha City \\
\hline 07 & Tabouk Region & Tabouk City \\
\hline 08 & Hail Region & Hail City \\
\hline 09 & Northern Border Region & Arar City \\
\hline 10 & Jizan Region & Jizan City \\
\hline 11 & Najran Region & Najran City \\
\hline 12 & Baha Region & Baha City \\
\hline 13 & Al-Jouf Region & Sikaka City \\
\hline
\end{tabular}

The administrative regional division of the Kingdom of Saudi Arabia is included by the Royal Decree No. A/92 dated $27 / 8 / 1412 \mathrm{H}$ is based on the regional government system and is regarded as the basis of collection, distribution, and publication of geographical and statistical data, where the Kingdom is divided into 13 regions as follows in the Table I:

The Administrative Region is divided into several governorates, its numbers differ from one region to another. The governorate is divided into municipalities that are administratively related to governorates of Emarah. These Administrative Regions in KSA can be illustrated in the following Map 1:

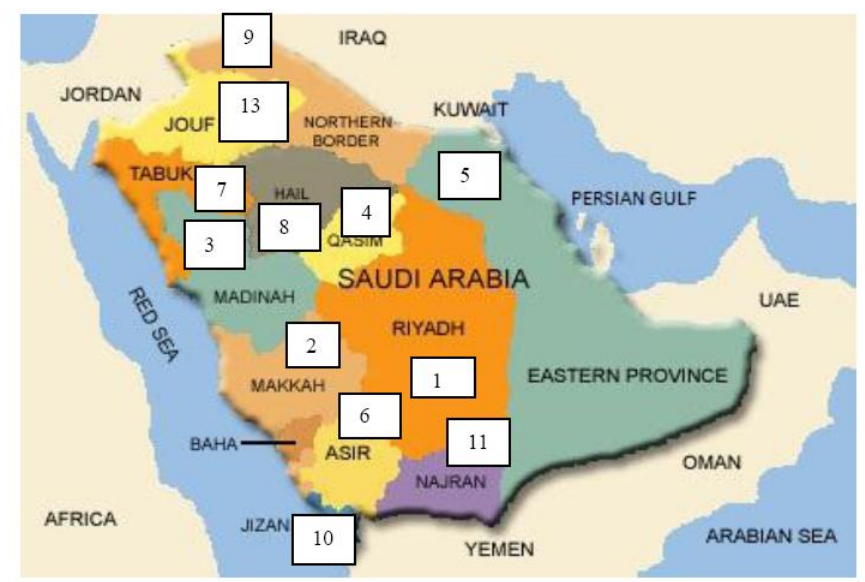

Map 1.The administrative regional divisions of the kingdom of Saudi Arabia [17].

It is worth noting that the relationship between the student and the central admission system includes a request from the student as a user either new or old, to E-student system, then a request from E-student system to the observation system in the central admission system within Saudi universities. According to this request, there will be a response from the observation system to E-student system, then a response from E-student system to the user. This can be shown in the following figure:

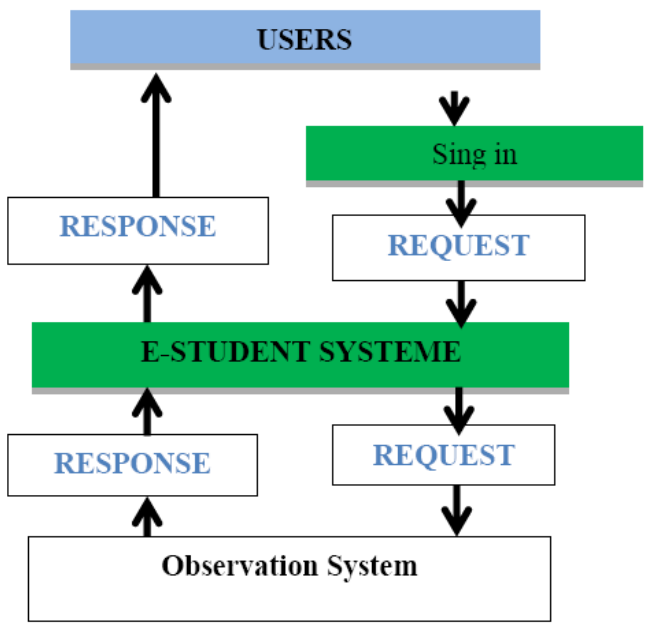

Fig. 4. The relationship between the student and the central admission system.

\section{A. Prototype Implementation}

The proposed system includes a central admission system website that is for student registration in Saudi universities. The website is designed with HTML. Each university will 
have an account or more on the website to check and follow up the student's requests. The website is designed to divide the users into three types: Student, Employee, and Administrator. The responsibilities of the three types will be as follows:

\section{1) The responsibilities of student include}

- The student must register in the website in order to be able to apply for a faculty.

- The student has the option to submit requests to apply for faculty ordered by the student's priority.

- The student will be able to check his requests status at any time.

- If a decision is taken for the student's request, the student will receive an automatic email.

\section{2) The responsibilities of employee include}

- The employee is able to display and search for student's requests.

- The employee is able to accept the student in a faculty inside a university according to his grade and requests.

\section{3) The responsibilities of administrator include}

- The administrator has the full privileges over the website.

- The administrator is able to make access at any time.

- The administrator is able to maintain the system.

The website is created with ASP.net Language using visual basic. The system identifies the user types on the login stage, and displays the different proper options for each type of users.

\section{B. Prototype Evaluation}

By comparing between the current system and the proposed system based on distributed questionnaires, we can evaluate the prototype. Because the students introduce many requests to more than one university, the current admission system in
Saudi universities gives them acceptance in more than one university. Doing so leads to wasting many chances for other students. The proposed system accepts only one request from each student in all universities. On the other hand, it helps the universities have only one place to receive the students' requisitions.

There are some advantages of the proposed systems; these advantages and benefits include:

- It accepts specific requests for each student in all universities.

- It provides one place for each student in all universities.

- It provides a consolidated data to help the decision makers to take the proper decision at the proper time.

- It gives students all available chances to get the best faculty according to their requests and grade under the student's priority.

However, there are some disadvantages and limitations of the proposed systems; these include:

- In the beginning of implementing the proposed system, it needs a big effort, cost, and time for implementation.

- It gives each student only one place according to his requests and his grade under the student's priority.

- It needsregular updating.

\section{THE PROPOSED PROGRAM}

According to the proposed program as a software program, the user should enter the Ministry of Higher Education website by signing in if he or she has an account (old user). If the user doesn't have an account (new user), he or she must sign up and create an account, as follows:

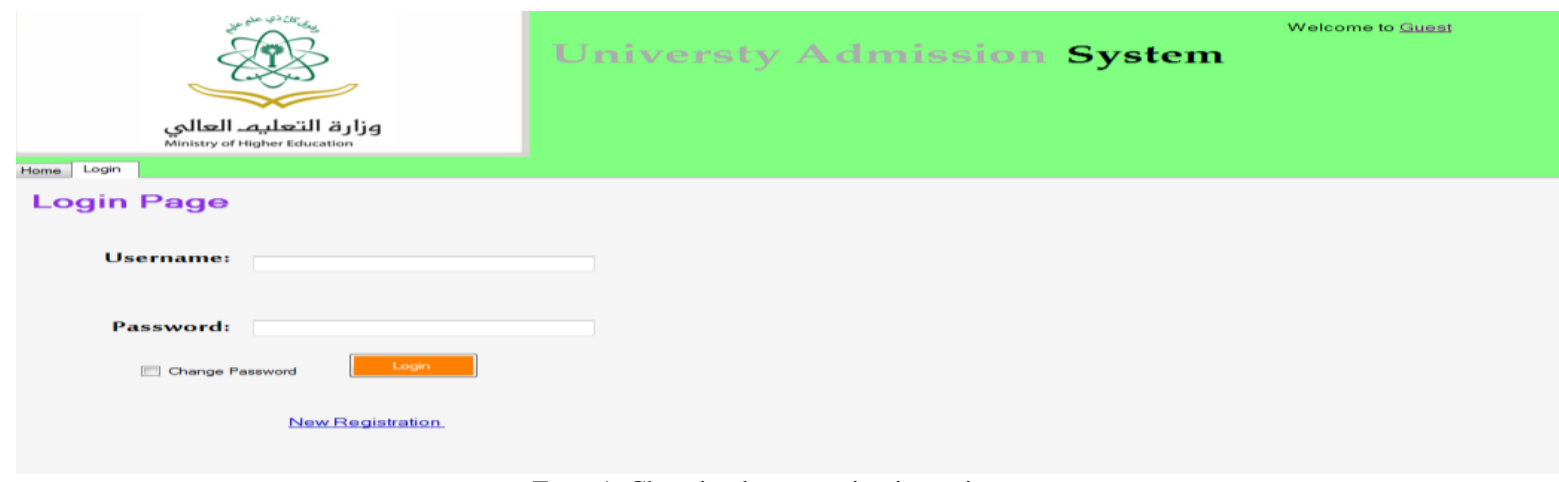

Form 1. Choosing between sign in or sign up

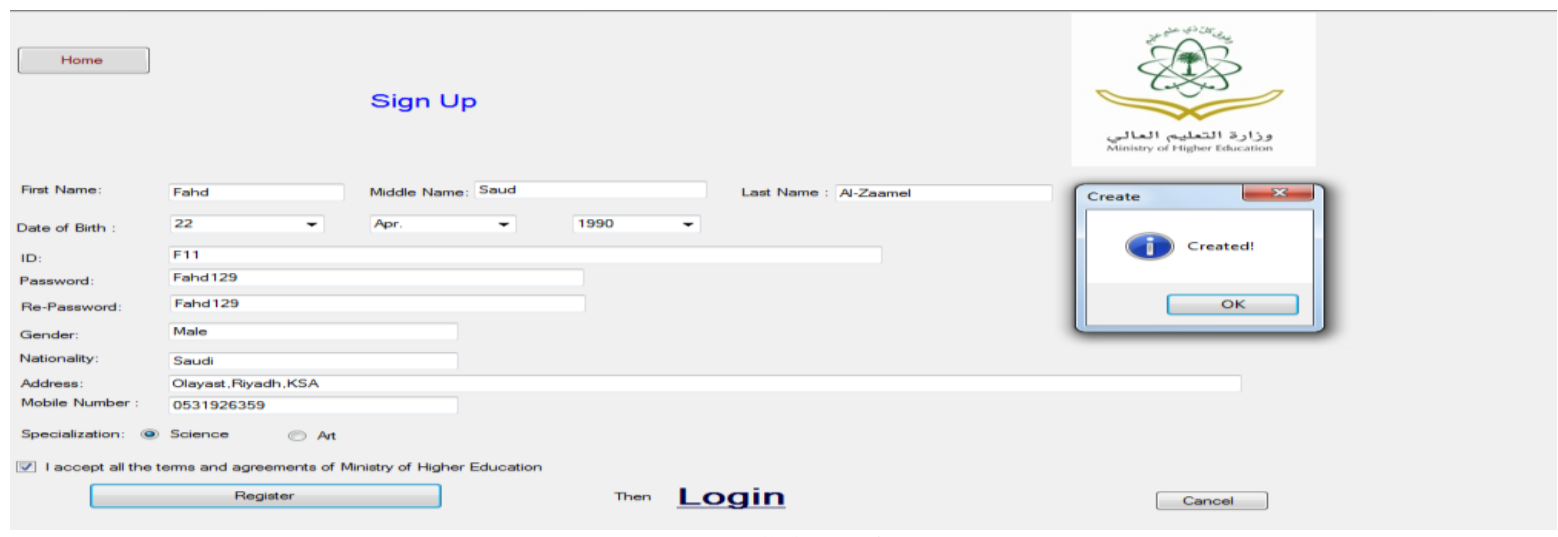

Form 2. Full sign up form. 


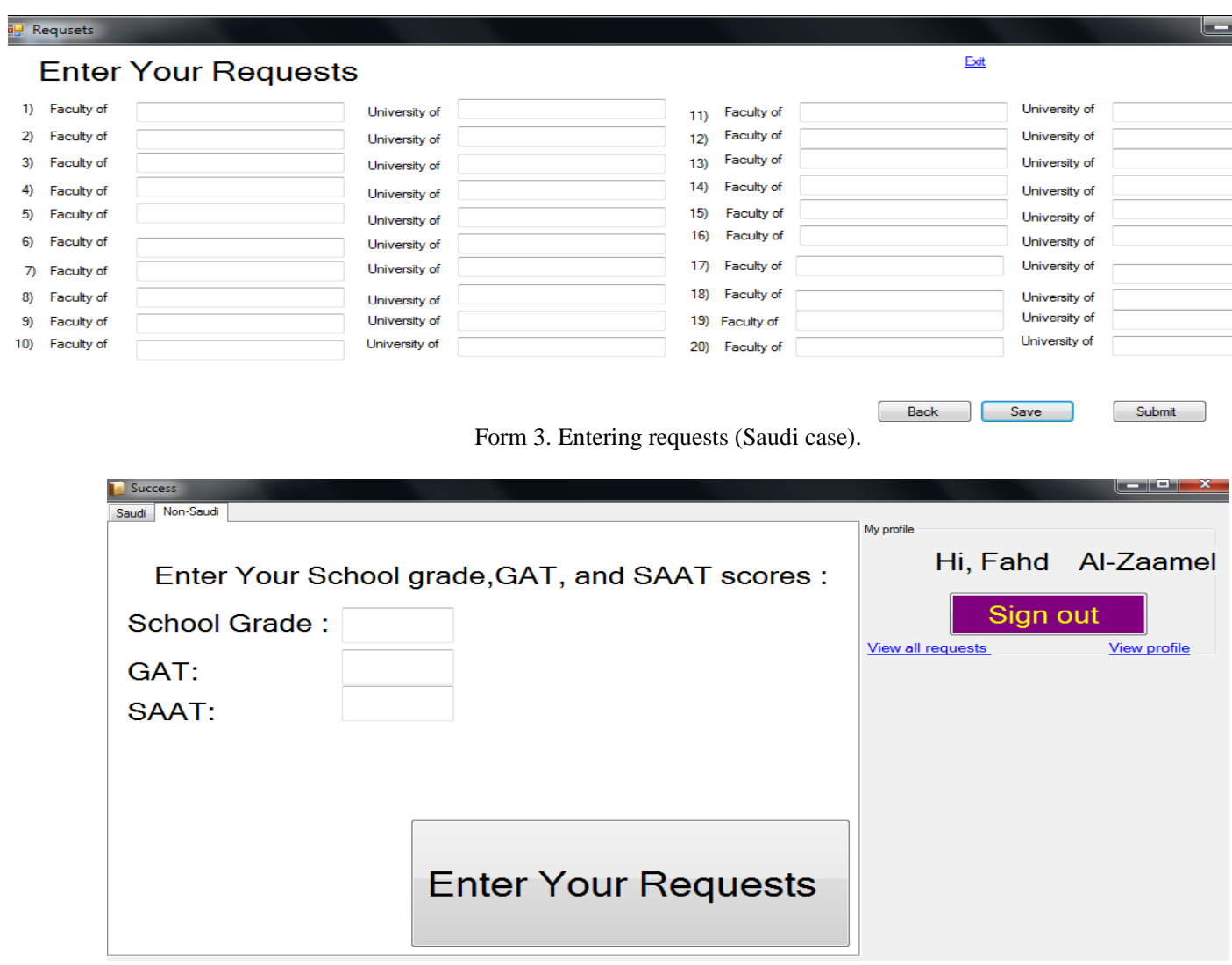

Form 4. Entering school, GAT, \& SAAT Scores (non-Saudi case).

To create an account, you should fill the form above.

To enter requests, you should sign in to the Ministry of Higher Education website. Then, choose between Saudi and non-Saudi. If you chose Saudi, you should choose between your getting your grade from inside or outside KSA. Then, you are asked to fill your requests according to your grade. If your grade is $90 \%$ or higher, you will be in the first stage. If your grade is $75 \%$ to less than $90 \%$, you will be in the second stage. If your grade is $60 \%$ to less than $75 \%$, you will be in the third stage, as illustrated in the following forms:

If the user wants to update his profile, he or she needs to explore his or her profile as in the following form:

\section{CRItical Review}

In spite of the benefits of the proposed systems, this system needs huge effort, cost, and time for implementation. It needs, also, regular update based on new circumstances, especially the development in IT. It gives each student only one place based on his or her requests and his or her grade (GPA) under the student's priority. Thus, this system depends solely on the academic ability of each student in admission. Therefore, it needs to develop in order to consider other factors in the future. Doing so will save resources and help the decision-makers take the proper decision at the proper time. In addition, it is necessary to develop administrators' skills from time to time to meet the requirements.

\section{CONCLUSION}

This paper has presented a framework for designing and implementing a system for the admission in the Saudi universities. It described the main features of the proposed system for the admission system in the Saudi universities. It, also, described the main elements of the proposed system. In addition, it presented the importance of the proposed system. Finally, it presented advantages and limitations of the proposed system.

\section{REFERENCES}

[1] UNESCO, World Data on Education, 6th Edition, IBE, Saudi Arabia, 2005/2007.

[2] The World Bank, "The road not travelled: Education reform in the Middle East and North Africa," World Bank 2008 Education Flagship Report, p. 105. 2008.

[3] Kingdom of Saudi Arabia. (2005). Ministry of Education. [Online]. Available: http://www.moe.gov.sa/openshare/englishcon/

[4] A. A. Elimam, "A decision support system for university admission policies," European Journal of Operational Research, vol. 50, pp 140-156, North-Holland, 1991.

[5] B. C. Sanyal, "The use of computerized information systems to increase efficiency in university management," International Institute for Educational Planning, Paris, 1995.

[6] A. Hamdan, "Women and education in Saudi Arabia: Challenges and achievements," International Education Journal, vol. 6, no. 1, pp 42-64, 2005.

[7] S. Mansmann and M. H. Scholl, "Decision support system for managing educational capacity utilization," IEEE Transactions on Education, vol. 50, no. 2, p. 143, May 2007.

[8] M. S. Garcia-Cascales and M. T. Lamata, "Information system for the valuation the universities in Spain," 2009.

[9] V. P. Bresfelean, N. Ghisoiu, R. Lacurezeanu, and D. Sitar-Taut, "Towards the development of decision support in academic environments," presented ar the ITI 2009 31st Int. Conf. on Information Technology Interfaces, June 22-25, 2009, Cavtat, Croatia.

[10] S. F. M. Dahlan and N. A. Yahaya, "A system dynamics model for determining educational capacity of higher education institutions," presented at Second International Conference on Computational Intelligence, Modelling and Simulation, 2010.

[11] S. A. Bhatti and A. Adnan, "Challenges in education management information system in develpoing countries," in Proc. Int. Conf. on Information and Emerging Technologies, IEEE, pp. 1-6, 2010. 
[12] R. Vohral and N. N. Das, "Intelligent decision support systems for admission management in higher education institutes," International Journal of Artificial Intelligence \& Applications, vol. 2, no. 4, pp. 63-70, 2011.

[13] PC Magazine. (2012). Wikipedia, the free encyclopedia. [Online]. Available: http://en.wikipedia.org/wiki/Prototype.

[14] How Stuff Works. (June 2014). Contributors. What Is a Prototype? [Online].

Available: http://home.howstuffworks.com/home-improvement/construction/pla nning/what-is-a-prototype.htm

[15] Wikipedia. (June 2014). The free encyclopedia. Prototype. [Online]. Available: http://en.wikipedia.org/wiki/Prototype.

[16] (June 2014). Images for map of Saudi Arabia Provinces. Images. [Online]. Available: https://www.google.com.sa/search?q=map+of+saudi+arabia+provinc
es\&revid=633365502\&sa=X\&ei=viSLUs7sAcyb1AWxv4HwCg\&ve $\mathrm{d}=0$ CKQBENUCKAU\&biw $=1280 \& \mathrm{bih}=833$

[17] Kingdom of Saudi Arabia. (September 2004). Public Administration. Country Profile. [Online]. Available: http://unpan1.un.org/intradoc/groups/public/documents/un/unpan023 182.pdf

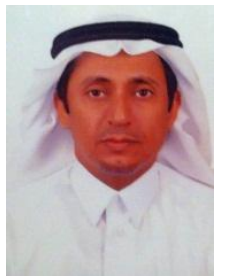

Awad G. Alotaibi was born in Riyadh on September 2, 1970. He is a Ph.D. student at De Montfort University now. He has good knowledge and ability of administrative affairs from planning, organization, implementation and organization. 